\title{
MODELAGEM DE INTERNAÇÕES POR DOENÇAS RESPIRATÓRIAS EM IDOSOS PELA SENSAÇÃO TÉRMICA NO MUNICÍPIO DE NATAL-RN
}

\author{
Ana Carla dos Santos Gomes ${ }^{1}$, Allan Rodrigues Silva², Maytê Duarte Leal Coutinho³, Micejane da Silva \\ Costa $^{4}$, Thalyta Soares dos Santos ${ }^{5}$
}

1,2,3,4,5 Doutorado em Ciências Climáticas da Universidade Federal do Rio Grande do Norte, UFRN. Email: anacarlasg02@gmail.com

\section{RESUMO}

Este trabalho teve por objetivo captar associações significativas entre internações e variáveis meteorológicas no município de Natal-RN, situado em uma região litorânea do nordeste brasileiro. Foram utilizados dados de velocidade do vento e temperatura do ar e de internações por doenças respiratórias em idosos (60 anos ou mais), no período de 2002 a 2010. O modelo marginal das equações de estimação generalizada não conseguiu captar associações significativas quando levou em consideração o efeito direto das variáveis meteorológicas, porém quando ajustado com o efeito em conjunto das mesmas, captou a relação existente com significância estatística.

\section{SUMMARY}

This work aimed to get significant associations between hospitalizations and meteorological variables in Natal-RN, located in a coastal region of northeastern Brazil. We used data from wind speed, air temperature and hospitalizations for respiratory diseases in the elderly (60 years or more) in the period 2002-2010.The marginal model of generalized estimating equations failed to capture significant associations when it considered the direct effect of meteorological variables, but when adjusted in conjunction with the effect of the same, it got the existing relation with statistical significance.

\section{INTRODUÇÃO}

O corpo humano é, essencialmente, um dispositivo de temperatura constante. O calor é continuamente produzido através de processos corporais e dissipado de uma maneira regulada automaticamente para manter a temperatura do corpo no seu nível adequado apesar 
variações nas condições ambientes e dessa forma ter seu funcionamento normal (NIKOLOPOULOU e STEEMER, 2003). Porém, em idosos, nem todas às vezes a adequação da temperatura do corpo é possível, principalmente quando expostos à situações climáticas adversas e aos efeitos em conjunto de variáveis meteorológicas, sendo este um dos fatores que possibilitam o agravamento de doenças respiratórias (COELHO et al. 2010). Este trabalho tem como objetivo captar associações significativas por meio de modelo estatístico adequado a natureza dos dados.

\section{MATERIAIS E MÉTODOS}

Utilizaram-se dados de internações por doenças respiratórias (Laringite, Faringite, Traqueíte, Amigdalite, Bronquite, Bronquiolite, Asma e Influenza) em idosos (60 anos ou mais) residentes no município de Natal-RN, no período de 2002 a 2010, disponibilizados pelo departamento de informática do Sistema Único de Saúde - DATASUS. Os de temperatura do ar e velocidade do vento foram obtidos por meio do Banco de dados meteorológicos para ensino e pesquisa do Instituto Nacional de Meteorologia. Para detecção da associação, foi feito o uso do modelo para dados correlacionados, modelo marginal das equações de estimação generalizadas (MMEEG) que são empregadas a fim de obter estimativas confiáveis, levando em conta uma estrutura de correlação. A técnica estatística foi realizada com o auxílio do software estatístico livre R. Utilizando o pacote geepack (Generalized Estimating Equation Package) e a função geeglm (Fit Generalized Estimating Equations).

\section{RESULTADOS E DISCUSSÃO}

Na Figura 01, observa-se a variabilidade da velocidade do vento e da temperatura, os maiores valores em média são observados entre os meses de julho a dezembro, porém destacou-se o mês de abril, com a maior variabilidade. A temperatura do ar não apresenta amplitudes térmicas elevadas, porém, pode-se destacar que o período de junho a agosto as mesmas encontram-se mais amenas. 

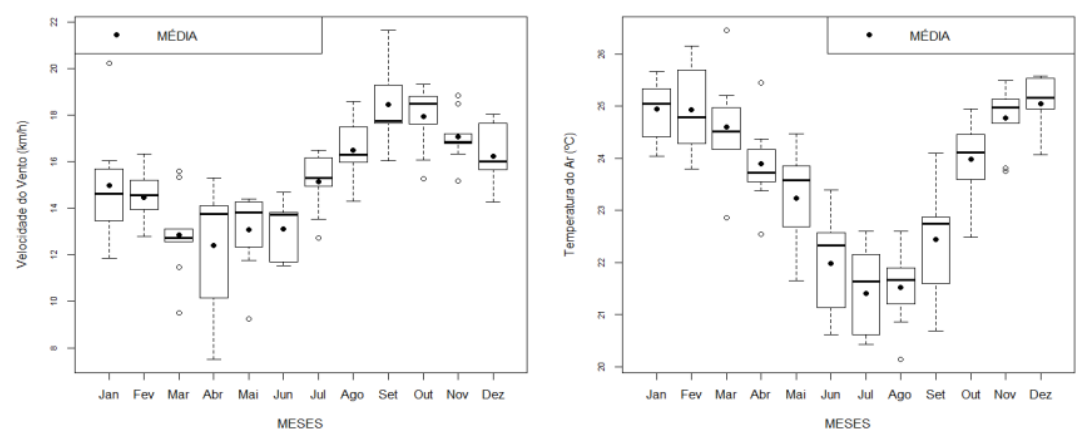

Figura 01- Gráfico de caixas da velocidade do vento e da temperatura do ar em NatalRN no período de 2002 a 2010.

Na Figura 02, observa-e que as variabilidades ao longo do ano são semelhantes. Destacandose os meses de julho e agosto que apontam para os menores valores e novembro a fevereiro os maiores, possivelmente contribuindo para a detecção da associação significativa, verificada na Tabela 01 .
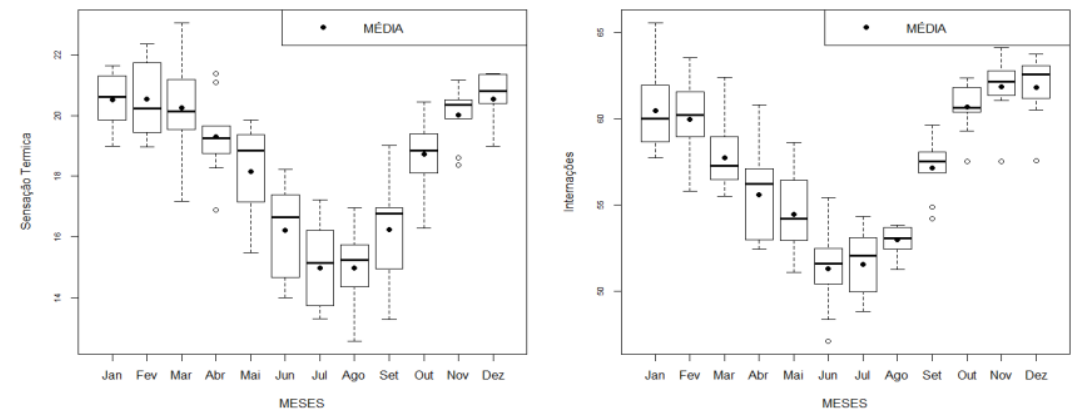

Figura 02 - Gráfico de caixas da Sensação Térmica e das Internações por doenças das vias aéreas superiores em idosos (60 anos ou mais) em Natal-RN no período de 2002 a 2010.

O MMEEG (Tabela 01), quando levou em consideração apenas o efeito único de cada uma das variáveis meteorológicas, não conseguiu captar associações significativas, porém ao incorporar o efeito em conjunto, foi possível captar e ajustar possibilitando a verificação da relação existente.

Tabela 01 - MMEEG's das Internações de Idosos (60 anos ou mais) por doenças respiratórias em Natal-RN, no período de 2002 a 2010. 


\begin{tabular}{lcccc}
\hline Modelos & $\begin{array}{c}\text { Variáveis } \\
\text { Explicativas }\end{array}$ & Estimativas & $\begin{array}{c}\text { Erro } \\
\text { Padrão }\end{array}$ & Valor-p \\
\hline Modelo 1 & Vel. do Vento & 0,253 & 0,172 & 0,14 \\
& Temp. do Ar & $-0,054$ & 0,140 & 0,70 \\
\hline Modelo 2 & Sensação & 3,226 & 0,041 & $<0,001$ \\
& Térmica & & & \\
\hline
\end{tabular}

Significância 5\%

Segundo Nikolopoulou e Steemers (2003), em ambientes externos, no qual as condições climáticas são difíceis de controlar, somente estas variáveis não são suficientes para explicar a percepção térmica, estas explicam $50 \%$ da avaliação subjetiva de conforto, indicando que variáveis psicológicas influenciam a avaliação do ambiente. Neste trabalho, os dados de sensação térmica tiveram sua interpretação subjetivamente, possibilitando permitir a verificação da modelagem estatística de forma adequada à natureza dos dados. A partir desses resultados preliminares, percebeu-se que os mesmos serviram para simulação de cenários futuros de quadros de doenças concordando com (COELHO et al. 2010).

\section{CONCLUSÃO}

Os resultados indicam que mesmo para modelos estatísticos sofisticados conseguirem captar associações significativas de forma adequada, só foi possível quando se agregou ao modelo informações das variáveis meteorológicas em conjunto, ou seja, informações da sensação térmica. $\mathrm{O}$ que permite indicar que o agravamento de doenças respiratórias nos idosos em Natal está diretamente relacionado aos valores da sensação térmica sentida pelos mesmos.

\section{REFERÊNCIAS}

COELHO, M.S.Z.S. ; LUIZ T. G., F.; ROSÁRIO M. O. L., Statistical Analysis Aiming at Predicting Respiratory Tract Disease Hospital Admissions From Environmental Variables in The City of São Paulo. Journal of Environmental and Public Health. v. 2010, P. 1-12, 2010. NIKOLOPOULOU, M.; STEEMER, K. Thermal comfort and psychological adaptation as a guide for designing urban spaces. Energy and Building, v.35, n.1, p.95-101, 2003, 